\title{
Marked potentiation of cell swelling by cytokines in ammonia-sensitized cultured astrocytes
}

\author{
Kakulavarapu V Rama Rao ${ }^{1}$, Arumugam R Jayakumar ${ }^{1,3}$, Xiaoying Tong ${ }^{1}$, Veronica M Alvarez ${ }^{3}$, \\ Michael D Norenberg ${ }^{1,2,3^{*}}$
}

\begin{abstract}
Background: Brain edema leading to high intracranial pressure is a lethal complication of acute liver failure (ALF), which is believed to be cytotoxic due to swelling of astrocytes. In addition to the traditional view that elevated levels of blood and brain ammonia are involved in the mechanism of brain edema in ALF, emerging evidence suggests that inflammatory cytokines also contribute to this process. We earlier reported that treatment of astrocyte cultures with a pathophysiological concentration of ammonia $\left(5 \mathrm{mM} \mathrm{NH}_{4} \mathrm{Cl}\right)$ resulted in the activation of nuclear factor-kappaB (NF- $\kappa \mathrm{B}$ ) and that inhibition of such activation diminished astrocyte swelling, suggesting a key role of NF- $\kappa \mathrm{B}$ in the mechanism of ammonia-induced astrocyte swelling. Since cytokines are also well-known to activate NF- $\kappa$ B, this study examined for additive/synergistic effects of ammonia and cytokines in the activation of $\mathrm{NF}-\kappa \mathrm{B}$ and their role in astrocyte swelling.
\end{abstract}

Methods: Primary cultures of astrocytes were treated with ammonia and cytokines (TNF- $\alpha, \mathrm{IL}-1, \mathrm{~L}-6$, IFN- $\gamma$, each at $10 \mathrm{ng} / \mathrm{ml})$, individually or in combination, and cell volume was determined by the $\left[{ }^{3} \mathrm{H}\right]$-O-methylglucose equilibration method. The effect of ammonia and cytokines on the activation of NF- $\kappa \mathrm{B}$ was determined by immunoblots.

Results: Cell swelling was increased by ammonia (43\%) and by cytokines (37\%) at $24 \mathrm{~h}$. Simultaneous co-treatment with cytokines and ammonia showed no additional swelling. By contrast, cultures pretreated with ammonia for $24 \mathrm{~h}$ and then exposed to cytokines for an additional $24 \mathrm{~h}$, showed a marked increase in astrocyte swelling (129\%). Treatment of cultures with ammonia or cytokines alone also activated NF- $\kappa$ B (80-130\%), while co-treatment had no additive effect. However, in cultures pre-treated with ammonia for $24 \mathrm{~h}$, cytokines induced a marked activation of NF- $\kappa$ B (428\%). BAY 11-7082, an inhibitor of NF- $\kappa$ B, completely blocked the astrocyte swelling in cultures pre-treated with ammonia and followed by the addition of a mixture of cytokines.

Conclusion: Our results indicate that ammonia and a mixture of cytokines each cause astrocyte swelling but when these agents are added simultaneously, no additive effects were found. On the other hand, when cells were initially treated with ammonia and $24 \mathrm{~h}$ later given a mixture of cytokines, a marked potentiation in cell swelling and NF- $\kappa \mathrm{B}$ activation occurred. These data suggest that the potentiation in cell swelling is a consequence of the initial activation of NF- $\kappa$ B by ammonia. These findings provide a likely mechanism for the exacerbation of brain edema in patients with ALF in the setting of sepsis/inflammation.

\section{Background}

Hepatic encephalopathy (HE) is a neurological disorder that presents in chronic and acute forms. Chronic HE is a neuropsychiatric disorder which commonly occurs in the setting of alcoholic cirrhosis and is associated with

\footnotetext{
* Correspondence: mnorenbe@med.miami.edu

'Department of Pathology, University of Miami Miller School of Medicine, Miami, FL 33125, USA

Full list of author information is available at the end of the article
}

changes in personality, altered mood, decline in the intellectual capacity and abnormal muscle tone [1]. Acute HE (acute liver failure, ALF) usually occurs following viral-mediated hepatitis, acetaminophen toxicity, and exposure to other hepatotoxins. ALF often presents with the abrupt onset of delirium, seizures and coma and has a high mortality rate (80-90\%) [2]. A major component of ALF is the development of brain edema leading to increased intracranial pressure and brain
C Biomed Central

(c) 2010 Rama Rao et al; licensee BioMed Central Ltd. This is an Open Access article distributed under the terms of the Creative Commons Attribution License (http://creativecommons.org/licenses/by/2.0), which permits unrestricted use, distribution, and reproduction in any medium, provided the original work is properly cited. 
herniation, ultimately resulting in death [3]. There is currently no satisfactory treatment for the edema in ALF except for an emergency liver transplantation [4].

The preponderance of evidence indicates that the brain edema in ALF is "cytotoxic", i.e., due to astrocyte swelling [5-9]. It has traditionally been considered that ammonia represents a major etiological factor in the development of neurological abnormalities associated with severe liver failure, including cytotoxic brain edema/astrocyte swelling $[6,10]$. Astrocytes primarily detoxify ammonia by converting glutamate into glutamine through a reaction mediated by glutamine synthetase, an enzyme predominantly present in astrocytes [11]. Accordingly, several studies document that a pathophysiological concentration of ammonia results in astrocyte swelling in culture [12-14], brain slices $[15,16]$ and in vivo models of hyperammonemia $[6,17,18]$. The mechanism by which ammonia and the subsequent production of glutamine leads to astrocyte swelling/brain edema is incompletely understood, but appears to involve the development of oxidative/nitrosative stress, the mitochondrial permeability transition and activation of mitogen activated protein kinases. For review, see [19].

In addition to ammonia, emerging evidence suggests that proinflammatory cytokines, likely derived from liver necrosis and/or sepsis (the latter a common complication in ALF) play an important role in brain edema formation in ALF. In support of this view, blood levels of TNF- $\alpha$, IL-1 $\beta$ and IL- 6 were found elevated in patients with ALF who had concurrent infections [20-22]. Additionally, induction of endotoxemia was shown to exacerbate brain edema in an experimental model of hyperammonemia [23].

While the above studies strongly suggest the involvement of inflammatory cytokines in the brain edema of ALF, the effect of various cytokines on astrocyte swelling has thus far not been investigated. The present study therefore examined the effect of various inflammatory cytokines on astrocyte swelling, as well as investigated the potential additive/synergistic interactions between ammonia and cytokines on cell swelling in cultured astrocytes.

We recently documented that exposure of cultured astrocytes to a pathophysiological concentration of ammonia results in the activation (nuclear translocation) of the transcriptional factor NF- $\kappa \mathrm{B}$ and that inhibition of such activation caused a reduction in ammoniainduced astrocyte swelling [24]. As cytokines are also well-known to activate NF- $\kappa \mathrm{B}$, we examined whether ammonia and cytokines exert additive/synergistic effects in the activation of NF- $\kappa \mathrm{B}$ and whether such activation contributes to potential additive/synergistic effects on astrocyte swelling. Our studies show that a mixture of cytokines cause cell swelling in cultured astrocytes, and that sensitization of cultures with ammonia prior to treatment with cytokines caused a marked potentiation of both the activation of NF- $\kappa \mathrm{B}$ and astrocyte swelling.

\section{Methods \\ Materials}

3-O-methyl glucose was purchased from American Radio chemicals Inc, St. Louis, MO. Recombinant rat TNF- $\alpha$, IL- $\beta$, IL- 6 and IFN- $\gamma$, and all other reagents were obtained from Sigma-Aldrich, St. Louis, MO.

\section{Astrocyte cultures}

Primary cultures of astrocytes were prepared from cerebral cortices of 1-2 day old rats as described earlier [25]. Briefly, cortices were freed of meninges, minced and dissociated by trituration, passed through sterile nylon sieves and then placed in Dulbecco's modified Eagle medium (DMEM) containing penicillin, streptomycin, and $15 \%$ fetal bovine serum. Approximately $0.5 \times 10^{6}$ cells were seeded in $35 \mathrm{~mm}$ culture plates and maintained at $37^{\circ} \mathrm{C}$ in an incubator equilibrated with $5 \% \mathrm{CO}_{2}$ and $95 \%$ air. Cultures consisted of $95-99 \%$ astrocytes based on immunohistochemical staining with glial fibrillary acidic protein. After 14 days, cultures were treated and maintained with dibutyryl cAMP to enhance cell differentiation [26]. Three to four-week-old cells were used in these experiments.

\section{Cytokine and ammonia treatment}

Astrocyte cultures were treated with rat recombinant TNF- $\alpha$, IL-1 $\beta$, IL- 6 and IFN- $\gamma$, all $10 \mathrm{ng} / \mathrm{ml}$ each, either individually or in combination for 3-24 h. For ammonia treatment studies, cultures were exposed to a pathophysiological concentration of ammonia $\left(5 \mathrm{mM} \mathrm{NH}_{4} \mathrm{Cl}\right)$; such concentration of ammonia is found in brains of experimental animals with ALF [27-29]. To examine the effect of prior treatment with ammonia followed by exposure to cytokines, cultures were first treated with ammonia for $24 \mathrm{~h}$, at which time a mixture of cytokines was added for an additional $24 \mathrm{~h}$.

\section{Cell volume determination}

Cell volume (intracellular water space) was determined using the 3-O-methyl- $\left[{ }^{3} \mathrm{H}\right]$-glucose (OMG) method as described by Kletzien et al. [30] and modified for astrocyte cultures by Norenberg et al. [12]. In brief, cultured astrocytes were incubated with $\left[{ }^{3} \mathrm{H}\right]$ OMG $(1 \mathrm{mM}$ containing $1 \mu \mathrm{Ci}$ of radioactive OMG) (Sigma Aldrich, St. Louis, MO), and at the end of incubation, a small aliquot of medium was saved for specific activity determination. Cultures were washed three times with ice-cold buffer containing $290 \mathrm{mM}$ sucrose, $1 \mathrm{mM}$ Tris-nitrate (pH 7.4), $0.5 \mathrm{mM}$ calcium nitrate and $0.1 \mathrm{mM}$ phloretin. Cells were harvested in $0.5 \mathrm{ml}$ of $1 \mathrm{~N}$ sodium hydroxide. Radioactivity was converted to intracellular water space 
and expressed as $\mu \mathrm{l} / \mathrm{mg}$ cell protein. Protein content was determined by the BCA method (Pierce, Rockford, IL).

\section{Preparation of nuclear extract and Western blots for NF- $\kappa$ B}

The nuclear extract was prepared as described previously [24]. In brief, astrocytes were harvested in $1 \mathrm{~mL}$ PBS and centrifuged at $735 \mathrm{~g}$ for $3 \mathrm{~min}$ at $4^{\circ} \mathrm{C}$. The cell pellet was suspended in a buffer containing $10 \mathrm{mM}$ HEPES ( $\mathrm{pH}$ 7.9), $10 \mathrm{mM} \mathrm{KCl,} 0.1 \mathrm{mM}$ EDTA, $0.1 \mathrm{mM}$ EGTA, $1 \mu \mathrm{M}$ dithiothreitol and a complete protease inhibitor cocktail (Roche, Mannheim, Germany); incubated on ice for $15 \mathrm{~min}$; $15 \mu \mathrm{L}$ of 10\% NP-40 (Roche Diagnostics Corp., Indianapolis, IN) was added and the sample was vortexed thoroughly for $40 \mathrm{~s}$ and centrifuged at $735 \mathrm{~g}$ for $3 \mathrm{~min}$ at $4^{\circ} \mathrm{C}$. The resulting nuclear pellet was resuspended in a buffer containing 20 mM HEPES (pH 7.9), 0.4 M NaCl, 1 mM EDTA, 1 mM EGTA, $1 \mu \mathrm{M}$ dithiothreitol and protease inhibitors and centrifuged at $16,000 \mathrm{~g}$ for $5 \mathrm{~min}$ at $4^{\circ} \mathrm{C}$. The supernatant was loaded on SDS polyacrylamide gels and Western blots were performed as described previously [24].

Antibodies against NF- $\kappa$ B-p65 (H-286) (Santa Cruz Biotechnology Inc, Santa Cruz, CA) and the nuclear marker lamin (Cell Signaling Technology, Beverly, MA) were used at 1:750 and 1:1000 dilutions, respectively. Horseradish peroxidase-conjugated anti-rabbit secondary antibody (1:1000) (Vector Laboratories, Burlingame, CA) was used. Membranes were visualized using an enhanced chemiluminescence reagent. The optical density of the bands was measured with the Chemi-Imager digital imaging system (Alpha Innotech Corp, San Leandro, CA) and the results were quantified with the Multi-Analyst software (Sigma Scan Pro 5; SPSS Inc., Chicago, IL) as a proportion of the signal of house-keeping protein band (lamin).

\section{Statistical analysis}

The data were expressed as means \pm SEM and analyzed by ANOVA followed by Neuman-Keuls multiple-range test. A p $<0.05$ was considered statistically significant.

\section{Results}

\section{Effect of cytokines on astrocyte cell volume}

Treatment of cultures with individual cytokines TNF- $\alpha$, IL- $1 \beta$, IL- 6 and IFN- $\gamma$ (10 ng/ml each) showed a timedependent increase in astrocyte swelling: at $3 \mathrm{~h}$ no astrocyte swelling was observed, while at $6 \mathrm{~h}$, a $27-32 \%$ cell swelling was identified after treatment with all cytokines, which persisted for up to $12 \mathrm{~h}$ (Figure 1). At $24 \mathrm{~h}$ cell swelling was non-significant (14\%) in cultures treated with TNF- $\alpha$, IL-1 $\beta$, IL-6. However, cultures treated with IFN- $\gamma$ continued to display cell swelling for up to $24 \mathrm{~h}(44 \pm 3 \%)$. We next examined the effect of a combination of cytokines (TNF- $\alpha$, IL- $1 \beta$, IL- 6 and IFN- $\gamma ; 10$ $\mathrm{ng} / \mathrm{ml} ; 24 \mathrm{~h}$ ) and found that such treatment resulted in

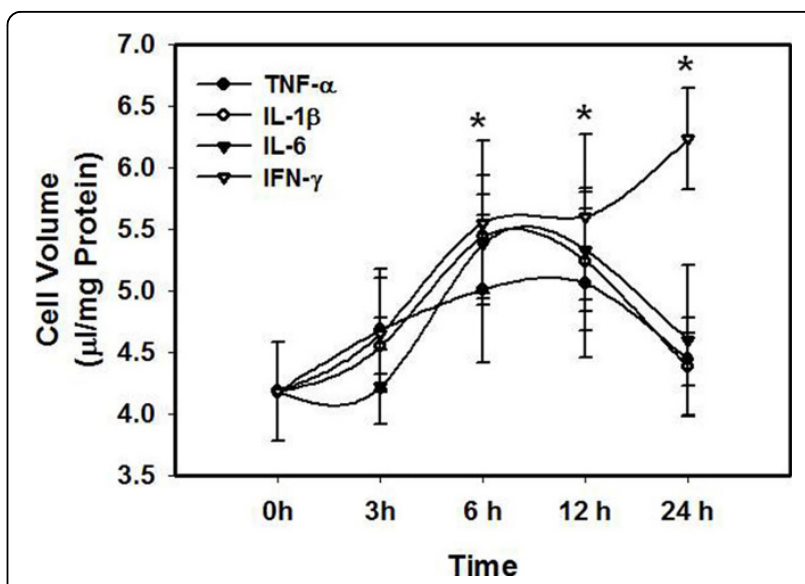

Figure 1 Time course of astrocyte cell volume following treatment with individual cytokines (TNF- $\alpha$, IL-1 $\beta$, IL-6 and IFN- $\gamma$ ). Cultures were treated with $10 \mathrm{ng} / \mathrm{ml}$ concentration of each cytokine. * vs. Control, $p<0.05$. Values in each group are mean \pm S.E.M of 5 individual culture plates taken from 3 separate seedings $(n=15)$.

a $38 \pm 2 \%$ increase in astrocyte cell volume (Figure 2); i.e., there was no difference in the degree of astrocyte swelling, when cultures were treated with cytokines individually or as a mixture.

\section{Effect of cytokines plus ammonia on astrocyte cell volume}

Ammonia is known to cause astrocyte swelling [12]. We therefore examined whether any additive/synergistic effects exist between ammonia and cytokines in the induction of cell swelling. Simultaneous co-treatment (24 h) of cultures with ammonia and cytokines showed no additive effects on astrocyte swelling (Figure 3 ).

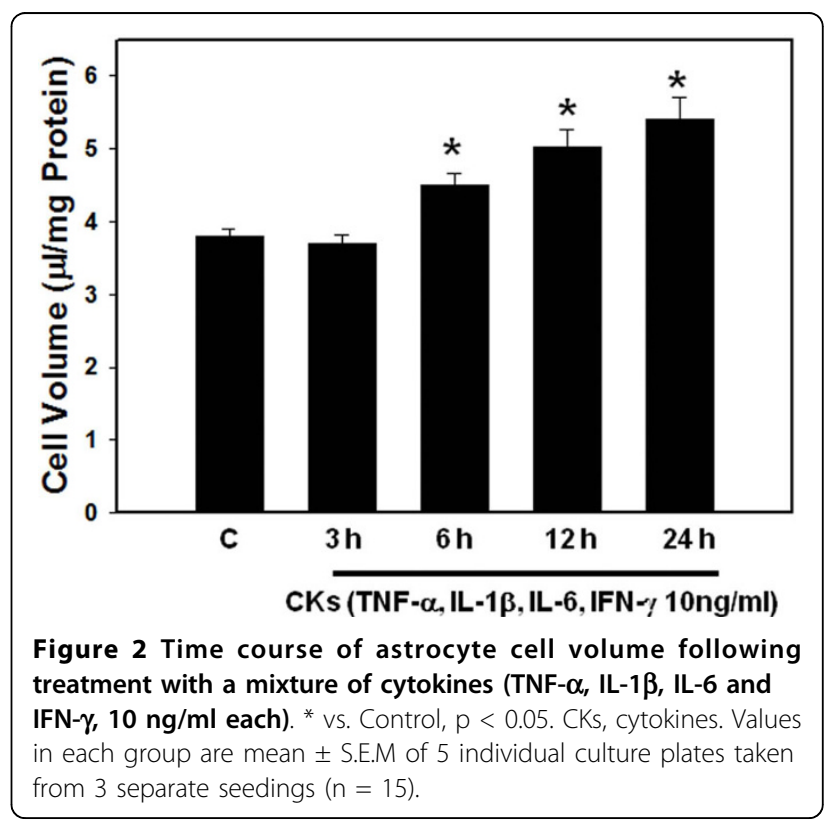




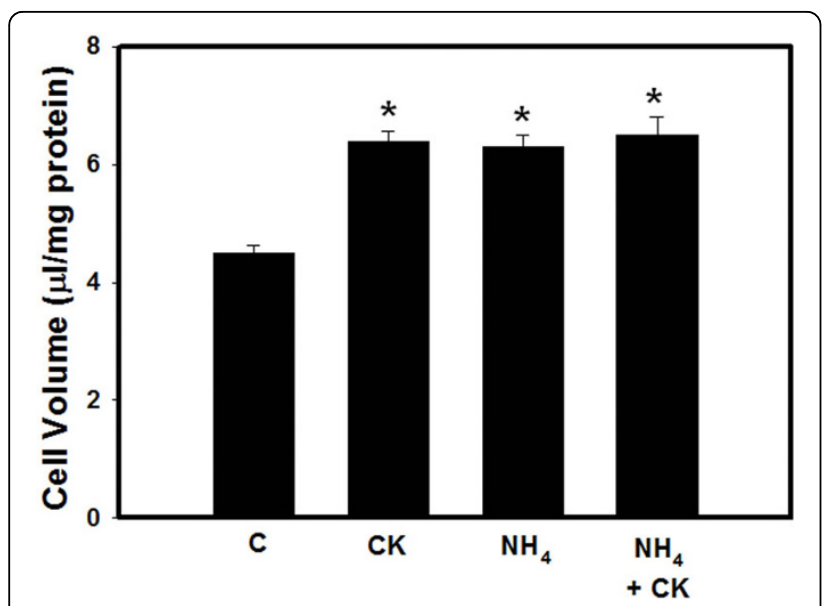

Figure 3 Effect of a co-treatment of ammonia and a mixture of cytokines on cell volume ( $24 \mathrm{~h})$ in cultured astrocytes. ${ }^{*}$ vs. Control, $p<0.05$. Values in each group are mean \pm S.E.M of 4 individual culture plates taken from 3 separate seedings $(n=12)$

Since in the clinical setting of ALF, elevated ammonia levels in blood/brain typically precedes inflammatory responses that might arise from liver necrosis and/or sepsis, we examined whether exposure of cytokines to ammonia-sensitized astrocytes showed additive or synergistic effects on astrocyte swelling. Cultures were treated with ammonia for $24 \mathrm{~h}$ and then exposed to a mixture of cytokines for an additional $24 \mathrm{~h}$. Such treatment resulted in a marked potentiation of astrocyte swelling $(129 \pm 6 \%)$ (Figure 4) as compared to a simultaneous treatment of cultures with ammonia and a mixture of cytokines (Figure 3).

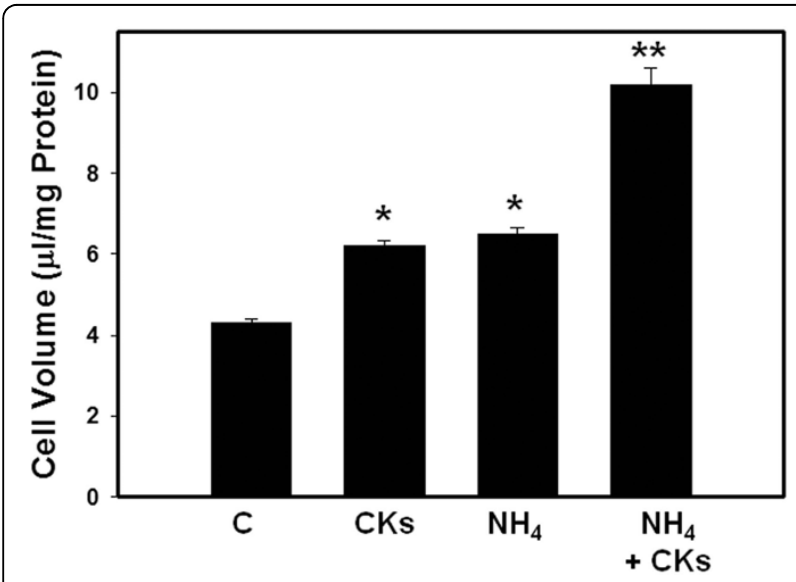

Figure 4 Synergistic effects on astrocyte cell volume by a pretreatment of cultures (sensitization) with ammonia followed by treatment with a mixture of cytokines on astrocyte cell volume (24 h). * vs. Control, $\mathrm{p}<0.05$; ** vs. CKs and $\mathrm{NH}_{4}, \mathrm{p}<0.05$. Values in each group are mean \pm S.E.M of 5 individual culture plates taken from 3 separate seedings $(n=15)$.
Effect of a mixture of cytokines on the activity of NF- $\kappa \mathrm{B}$ We recently documented that treatment of cultured astrocytes with ammonia results in the activation of the transcriptional factor NF- $\kappa \mathrm{B}$ as shown by an increase in its nuclear translocation, and that inhibition of such activation significantly attenuated ammonia-induced astrocyte swelling [24], indicating an important role of $\mathrm{NF}-\kappa \mathrm{B}$ in such swelling. Since cytokines are also known to activate NF- $\kappa \mathrm{B}$ [31], we examined the effect of a mixture of cytokines on NF- $\kappa \mathrm{B}$ activation. Treatment of cultures with ammonia resulted in a $100 \pm 10 \%(\mathrm{p}<$ $0.01)$ increase in the activation of NF- $\kappa \mathrm{B}$. Likewise, a mixture of cytokines significantly increased (96 $\pm 8 \%$ ) the activation of NF- $\kappa \mathrm{B}$ (Figure 5). Treatment of cultures with individual cytokines also resulted in NF- $\kappa \mathrm{B}$ activation in a time-dependent manner but the degree of such activation varied with each cytokine (Figure 6). However, a good correlation was observed between astrocyte swelling and the activation of NF- $\kappa \mathrm{B}$ by individual cytokines (Figures 1 and 6).

\section{Effect of a combination of ammonia and a mixture of} cytokines on the activity of NF- $\kappa \mathrm{B}$

Similar to the findings of astrocyte swelling, a simultaneous co-treatment $(24 \mathrm{~h})$ of cultures with ammonia and cytokines showed no additive/synergistic effects on NF- $\kappa$ B activation (Figure 5). However, in cultures previously treated with ammonia $(24 \mathrm{~h})$, the subsequent exposure of cells to a mixture of cytokines for an additional $24 \mathrm{~h}$ resulted in a marked increase in the activation of NF- $\kappa \mathrm{B}$ (428\%) (Figure 7). These findings strongly suggest that the marked potentiation of astrocyte swelling by

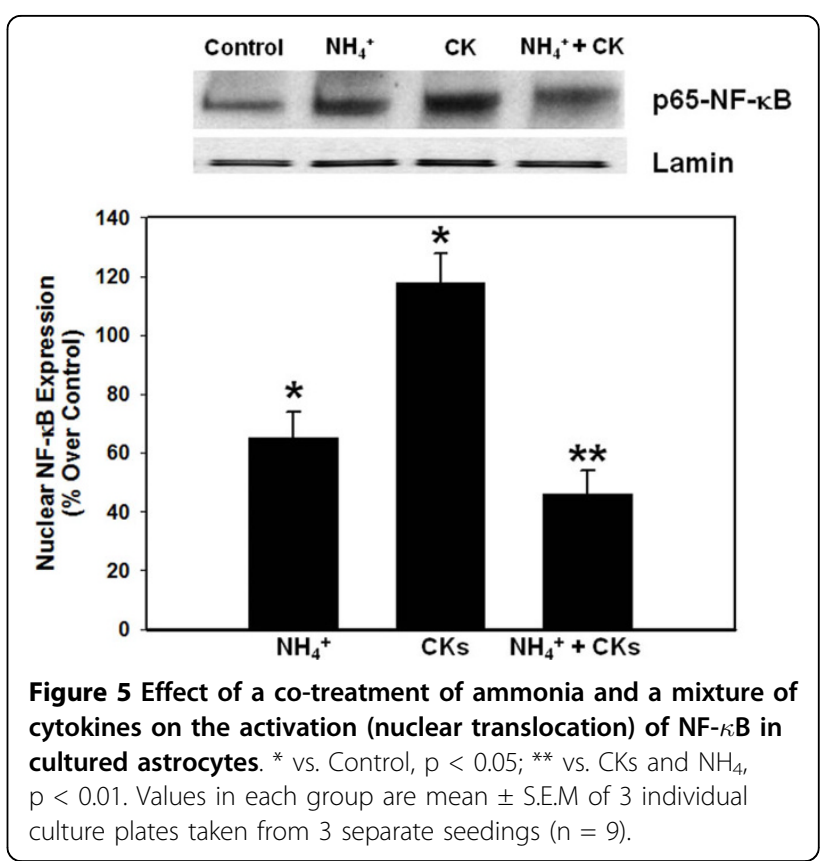




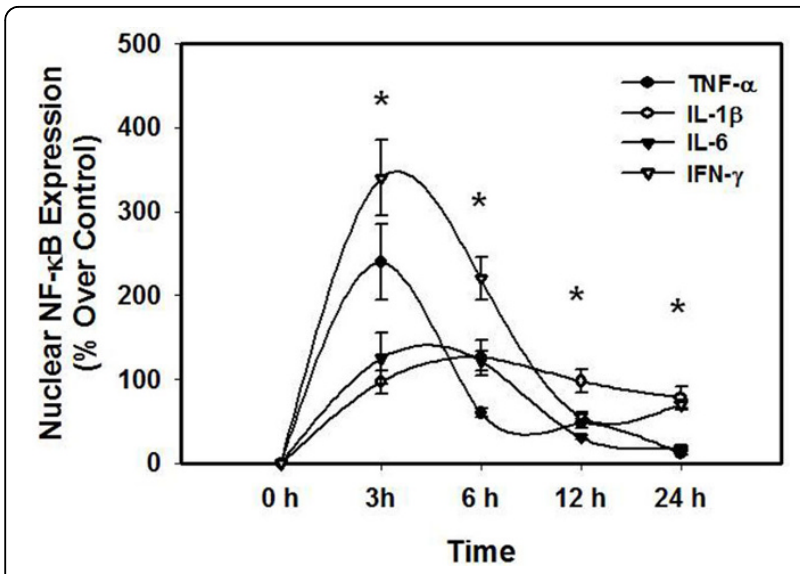

Figure 6 Time course of NF- $\kappa$ B activation following treatment with individual cytokines (TNF- $\alpha$, IL-1 $\beta$, IL- 6 and IFN- $\gamma, 10 \mathrm{ng} / \mathrm{ml}$ each). ${ }^{*}$ vs. Control, $p<0.05$. Values in each group are mean \pm S.E.M of 3 individual culture plates taken from 3 separate seedings $(n=9)$.

a pre-treatment with ammonia followed by a treatment with a mixture cytokines is a consequence of NF- $\kappa \mathrm{B}$ activation.

Effect of BAY 11-7082 on the astrocyte swelling produced by ammonia and cytokines

We earlier documented that BAY 11-7082, an inhibitor of NF- $\kappa \mathrm{B}$, significantly diminished ammonia-induced astrocyte swelling [24]. The present study found that

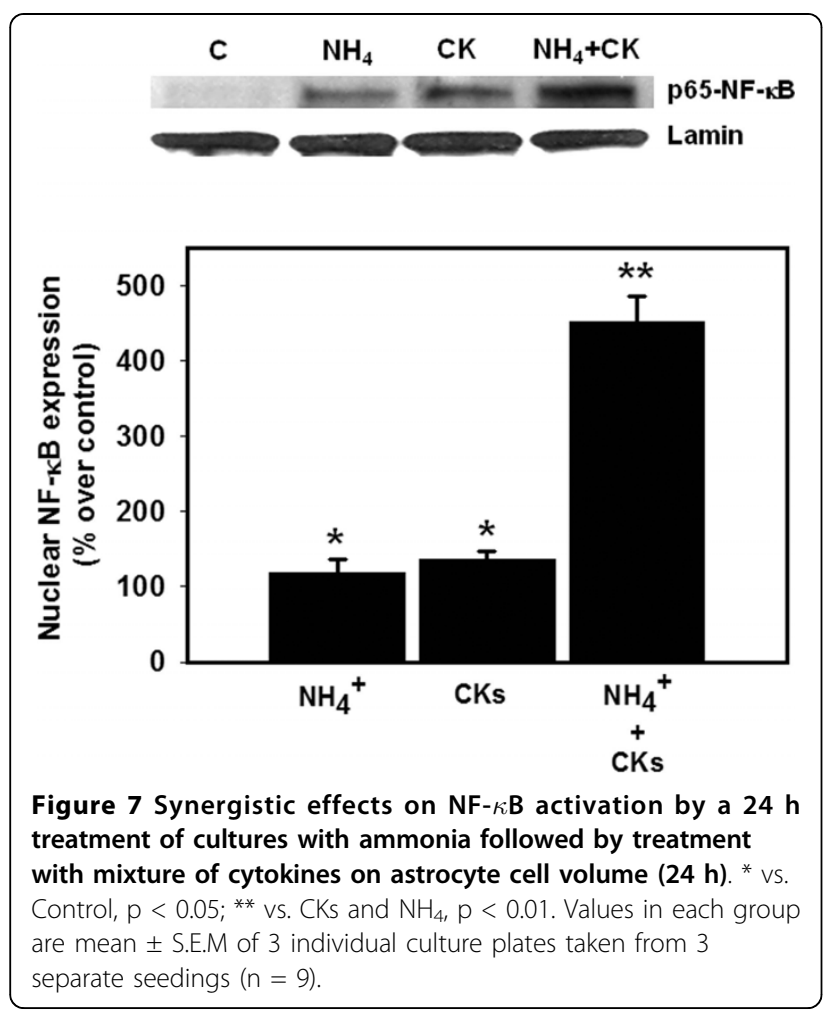

pretreatment of cultures with BAY 11-7082 diminished ammonia-induced astrocyte swelling (55\%), which is consistent with our previous observations [24]. Additionally, BAY 11-7082 completely blocked the astrocyte swelling caused by a mixture of cytokines, as well as completely blocked the potentiation in cell swelling in cultures exposed to ammonia followed 24 later by the addition of a mixture of cytokines (Figure 8).

\section{Discussion}

This study demonstrates that a combination of inflammatory cytokines, including TNF- $\alpha$, IL-1 $\beta$, IL- 6 and IFN- $\gamma$, as well as cytokines given individually, can induce astrocyte swelling. Simultaneous co-treatment of astrocytes with a pathophysiological concentration of ammonia and cytokines failed to elicit any additive/synergistic effect. However, treatment (24 h) of astrocyte cultures with ammonia prior to exposure to a mixture of cytokines for an additional $24 \mathrm{~h}$ resulted in a marked potentiation of astrocyte swelling. Treatment of cultures with a combination of cytokines, or cytokines given individually, resulted in the activation of NF- $\kappa \mathrm{B}$. Additionally, we observed that sensitization of cultures with ammonia before exposure to a mixture of cytokines resulted in a marked increase in the activation of NF- $\kappa \mathrm{B}$, similar to that observed with cell swelling. Treatment of cultures with BAY 11-7082, an inhibitor of NF- $\kappa \mathrm{B}$, completely blocked the potentiation effects of cell swelling of astrocytes sensitized by ammonia and subsequently treated with cytokines. Altogether, these data indicate that ammonia and cytokines independently cause the activation of NF- $\kappa \mathrm{B}$ and astrocyte swelling, and that pretreatment of cultures with ammonia sensitizes these cells to

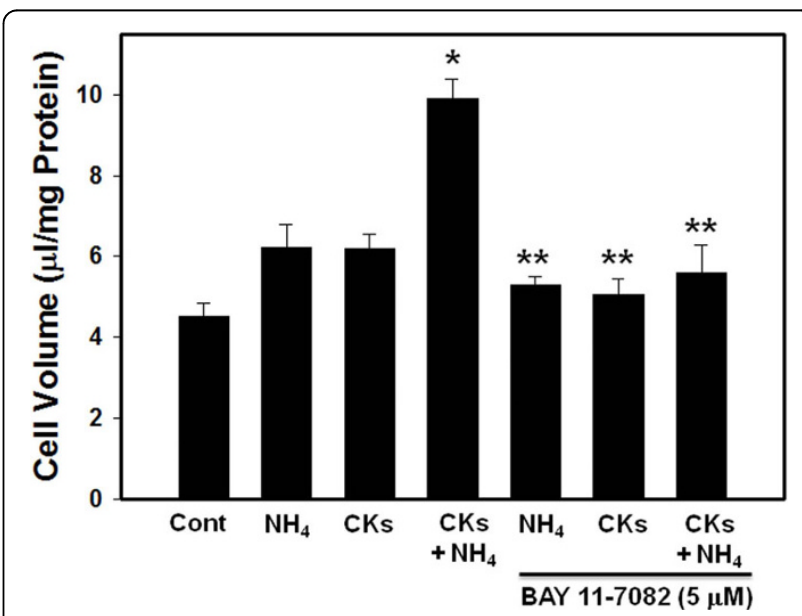

Figure 8 Effect of inhibition of NF- $\kappa$ B activation by $B A Y$ 11-7082 on astrocyte cell volume $(24 \mathrm{~h})$ induced by a mixture of cytokines and ammonia. ${ }^{*}$ vs. Control, $\mathrm{p}<0.05 ;{ }^{* *}$ vs. $\mathrm{CKs} ; \mathrm{NH}_{4}$ and $\mathrm{NH}_{4}+\mathrm{CKs}, \mathrm{p}<0.05$. Values in each group are mean \pm S.E.M of 5 individual culture plates taken from 3 separate seedings $(n=15)$. 
the effect of cytokines, resulting in a marked increase in both $\mathrm{NF}-\kappa \mathrm{B}$ activation and cell swelling, indicating a critical role of $\mathrm{NF}-\kappa \mathrm{B}$ in the potentiation of astrocyte swelling.

While ammonia continues to play a prominent role in the mechanism of brain edema in ALF, the findings of this study on the role of cytokines in the mechanisms of astrocyte swelling are highly pertinent and add to a growing body of evidence suggesting that inflammation and inflammatory cytokines also contribute to the brain edema in ALF [32-36]. The generation of cytokines is a consequence of extensive liver necrosis as well as infection/sepsis which frequently complicates ALF [20,37]. Additionally, lipopolysaccharide, a well-known inducer of inflammation [38], was shown to exacerbate brain edema in an experimental model of hyperammonemia [23]. Our observations on the marked potentiation of cell swelling by priming of cells with ammonia followed by treatment with cytokines in cultured astrocytes correspond well with the above clinical findings.

The present study also showed that TNF- $\alpha$, IL- $1 \beta$, or IL-6 given individually induces astrocyte swelling. Following treatment with these cytokines, astrocyte swelling was observed at $6 \mathrm{~h}$ and persisted for up to $12 \mathrm{~h}$; however, by $24 \mathrm{~h}$ no swelling was detected. These findings suggest that cell swelling produced by cytokines is an early but transient event. Consistent with our results, one study documented that treatment of cultured astrocytes with TNF- $\alpha$ for $48 \mathrm{~h}$ did not affect astrocyte cell volume [39]. Our findings are also consistent with a recent report showing that in transgenic mice deficient in TNF- $\alpha$, IL$1 \beta$ and IL- 6 receptors, ALF results in a lesser degree of brain edema as compared to levels achieved in wild-type mice [40]. To the best of our knowledge, this study documents for the first time that various inflammatory cytokines cause cell swelling in cultured astrocytes.

In contrast to TNF- $\alpha$, IL- $1 \beta$ and IL- 6 , IFN- $\gamma$ caused cell swelling which persisted for up to $24 \mathrm{~h}$. The reason for the different pattern of swelling observed with IFN- $\gamma$ is not known. The effect of IFN- $\gamma$, however, is at variance with a recent report noting that mice deficient in IFN- $\gamma$ receptors do not show a reduction in brain edema following the induction of ALF [40]. While the reason for the differences regarding the role of IFN- $\gamma$ in cell swelling/brain edema is not known, studies by Bemeur et al [40] noted that brain levels of IFN- $\gamma$ were not elevated in wild-type mice after the administration of azoxymethane, a model of ALF that results in death within 16-18 h. By contrast, using a rat model of ALF induced by the hepatotoxin thioacetamide, which displays a more protracted clinical course (death occurring at 72-80 h), we found a modest increase (32\%) in IFN- $\gamma$ in brain, while the levels of TNF- $\alpha$, IL- $1 \beta$ were elevated by $100-140 \%$ (unpublished observations). It is possible that differences in models of ALF, particularly in the rate of clinical progression and the degree of severity of liver failure, may be critical in the differential effects relative to the role of IFN- $\gamma$ in the brain edema associated with ALF.

The present study additionally showed that a mixture of all four cytokines resulted in astrocyte swelling; however, the degree of swelling caused by a combination of cytokines did not differ from that exerted by individual cytokines. The reason for the absence of a potential additive effect on cell swelling when cytokines were added as a mixture is not clear. It is possible that negative interactions among cytokines may have precluded an additive effect. Consistent with this view, it has been shown that treatment of cultured astrocytes with TNF- $\alpha$ and IFN- $\gamma$ showed no additive effects on the expression of complement (C3) genes, although individually these cytokines significantly enhanced $\mathrm{C} 3$ gene expression [41]. Additionally, IFN- $\gamma$ has been shown to antagonize the effect of TNF- $\alpha$ on the production of chemokines in human astrocytes [42].

A notable finding of this study was that treatment of cultures with ammonia for $24 \mathrm{~h}$ prior to treatment with a mixture of cytokines for additional $24 \mathrm{~h}$ resulted in a marked potentiation of astrocyte swelling. By contrast, co-treatment with ammonia and cytokines did not result in such potentiation on astrocyte swelling. These data suggest that ammonia sensitizes astrocytes to the effect of cytokines, thereby resulting in a potentiation of cell swelling. This pattern parallels the clinical findings in ALF whereby the initial hyperammonemia is often followed by an inflammatory response as a consequence of liver necrosis and/or sepsis [32,33].

The mechanism by which prior sensitization of cultures with ammonia followed by treatment with a mixture of cytokines results in a marked increase in astrocyte swelling is not well understood. It is, however, reasonable to suggest that sensitization of cultures with ammonia facilitates a process by which cytokines potentiate their effects on astrocyte swelling. Pertinent to this view, it was recently demonstrated that exposure of cultured astrocytes to ammonia results in the activation of NF- $\kappa \mathrm{B}$ as early as $12 \mathrm{~h}$. Such activation appears to be mediated by oxidative/ nitrosative stress (ONS), and activation of mitogen activated protein kinases (MAPKs) [24]. It is therefore possible that the initial activation of NF- $\kappa \mathrm{B}$ by ammonia (24 h ammonia sensitization) promotes a synergistic effect on NF- $\kappa \mathrm{B}$ activation after the addition of cytokines. This sequence is plausible as cytokines are well-known to activate NF- $\kappa$ B [31,43-45].

A parallel pattern observed between cell swelling and $\mathrm{NF}-\kappa \mathrm{B}$ activation supports the proposed key role of $\mathrm{NF}-\kappa \mathrm{B}$ in such astrocyte swelling. Thus, the time-course of activation of NF- $\kappa$ B by TNF- $\alpha$, IL- $1 \beta$ and IL- 6 , IFN- $\gamma$, correlate with the time-course of astrocyte 
swelling (Figures 1 and 6). Likewise, activation of NF- $\kappa \mathrm{B}$ by a mixture of cytokines resulted in a commensurate increase in astrocyte swelling. Further, the observation that BAY 11-7082, an inhibitor of NF- $\kappa \mathrm{B}$, completely diminished the synergistic effect on astrocyte swelling produced by cytokines after prior-sensitization of cultures with ammonia, adds credence to the key role of $\mathrm{NF}-\kappa \mathrm{B}$ in synergism on cell swelling.

While the time-course of cell swelling and that of NF- $\kappa \mathrm{B}$ activation by cytokines were similar, some inconsistencies were noted. Thus, while simultaneous co-treatment of cultures with ammonia and a mixture of cytokines continued to show astrocyte swelling, such treatment unexpectedly resulted in a significant reduction in NF- $\kappa \mathrm{B}$ activation as compared to cultures treated with ammonia or with a mixture of cytokines (Figure 5). The reason for this discordance is not known. However, it is possible that the presence of ammonia during the course of cytokine treatment might have interfered with the ability of cytokines to activate NF- $\kappa \mathrm{B}$. It should be noted that this condition is very different from the ammonia pretreatment protocol, as by the time cytokines were added, all of the ammonia had been metabolized and was no longer present in the culture media (data not shown).

We also observed that exposure of cultures to ammonia prior to treatment with a mixture of cytokines caused a marked activation of NF- $\kappa$ B (428\%), while the increase in astrocyte swelling was of lesser magnitude (129\%). The disparity between these two events is probably due to the fact that the extent of swelling observed (129\%) represents the maximal swelling capacity for astrocytes, as we previously documented that maximal increase in cell volume in cultured astrocytes incubated in hypoosmotic media was 120\% ([45] and references therein).

Precisely how NF- $\kappa \mathrm{B}$ contributes to astrocyte swelling is not clear. NF- $\kappa \mathrm{B}$ is known to activate various genes, including inducible nitric oxide synthase (iNOS) and NADPH oxidase (NOX) [31], whose products nitric oxide, superoxide and peroxynitrite have been shown to cause astrocyte swelling [46-48]. Additionally, NF- $\kappa \mathrm{B}$ is known to activate phospholipase A2 (PLA2) as well as cycooxygenase-2 (COX-2) [31], the products of which include arachidonic acid and prostaglandin E2, metabolites capable of inducing astrocyte swelling [49]. Consistent with this view, recent studies have also shown that ammonia activates iNOS, NOX, PLA2 and COX-2 and that inhibition of these enzymes diminished ammoniainduced astrocyte swelling [24,50-52]. Nevertheless, the precise pathway(s) by which NF- $\kappa \mathrm{B}$ activation contributes to astrocyte swelling remains to be established.

\section{Conclusions}

TNF- $\alpha$, IL- $1 \beta$, IL- 6 and IFN- $\gamma$, individually and in combination, caused cell swelling in cultured astrocytes and activation of NF- $\kappa \mathrm{B}$. Treatment of cultures with BAY 117082 significantly inhibited cytokine-mediated astrocyte swelling indicating a role of NF- $\kappa \mathrm{B}$ in such swelling. Additionally, sensitization of cultures with ammonia prior to treatment with cytokines potentiated both cell swelling and NF- $\kappa$ B activation. BAY 11-7082, an inhibitor of NF$\kappa \mathrm{B}$, completely diminished astrocyte swelling. Altogether, our findings demonstrate a critical role of NF- $\kappa \mathrm{B}$ in the potentiation of cell swelling created by ammonia pretreatment followed by exposure to a mixture of cytokines. These findings provide a potential explanation for the exacerbation of brain edema in the setting of sepsis/ inflammation, a frequent complication of ALF. Targeting $\mathrm{NF}-\kappa \mathrm{B}$ may provide a useful strategy for the treatment of the brain edema associated with ALF.

\section{Acknowledgements}

This work was supported by grants from the Department of Veterans Affairs Merit Review, the NIH (DK063311), the American Association for Study of Liver Diseases and the American Liver Foundation. We are grateful to Alina Fernandez for preparation of astrocyte cultures.

\section{Author details}

'Department of Pathology, University of Miami Miller School of Medicine, Miami, FL 33125, USA. ${ }^{2}$ Department of Biochemistry \& Molecular Biology, University of Miami Miller School of Medicine, Miami, FL 33125, USA. ${ }^{3}$ Veterans Affairs Medical Center, Miami, Fl, 33125, USA.

\section{Authors' contributions}

$K V R, A R J$, performed major parts of the experiments and $X Y$ and VMA assisted in some of the experiments. KVR, ARJ and MDN designed the experiments, analyzed the data and wrote the manuscript. All authors read and approved the final version of the manuscript.

\section{Competing interests}

The authors declare that they have no conflicts of interest either financially or non-financially in this study.

Received: 26 August 2010 Accepted: 13 October 2010

Published: 13 October 2010

\section{References}

1. Jones EA, Weissenborn K: Neurology and the liver. J Neurol Neurosurg Psychiatry 1997, 63:279-293.

2. Capocaccia L, Angelico M: Fulminant hepatic failure. Clinical features, etiology, epidemiology, and current management. Dig Dis Sci 1991, 36:775-779.

3. Blei AT: Cerebral edema and intracranial hypertension in acute liver failure: distinct aspects of the same problem. Hepatology 1991, 13:376-379.

4. Bismuth H, Samuel D, Castaing D, Williams R, Pereira SP: Liver transplantation in Europe for patients with acute liver failure. Semin Liver Dis 1996, 16:415-425.

5. Martinez A: Electron microscopy in human hepatic encephalopathy. Acta Neuropathol (Berl) 1968, 11:82-86.

6. Norenberg MD: A light and electron microscopic study of experimental portal-systemic (ammonia) encephalopathy. Progression and reversal of the disorder. Lab Invest 1977, 36:618-627.

7. Traber PG, Dal Canto M, Ganger DR, Blei AT: Electron microscopic evaluation of brain edema in rabbits with galactosamine-induced fulminant hepatic failure: ultrastructure and integrity of the blood-brain barrier. Hepatology 1987, 7:1272-1277.

8. Kato M, Sugihara J, Nakamura T, Muto Y: Electron microscopic study of the blood-brain barrier in rats with brain edema and encephalopathy due to acute hepatic failure. Gastroenterol Jpn 1989, 24:135-142. 
9. Chavarria L, Oria M, Romero-Gimenez J, Alonso J, Lope-Piedrafita S, Cordoba J: Diffusion tensor imaging supports the cytotoxic origin of brain edema in a rat model of acute liver failure. Gastroenterology 2010 138:1566-1573.

10. Blei AT, Olafsson S, Therrien G, Butterworth RF: Ammonia-induced brain edema and intracranial hypertension in rats after portacaval anastomosis. Hepatology 1994, 19:1437-1444.

11. Martinez-Hernandez A, Bell KP, Norenberg MD: Glutamine synthetase: glial localization in brain. Science 1977, 195:1356-1358.

12. Norenberg MD, Baker L, Norenberg LO, Blicharska J, Bruce-Gregorios JH, Neary JT: Ammonia-induced astrocyte swelling in primary culture. Neurochem Res 1991, 16:833-836.

13. Zwingmann C, Flogel U, Pfeuffer J, Leibfritz D: Effects of ammonia exposition on glioma cells: changes in cell volume and organic osmolytes studied by diffusion-weighted and high-resolution NMR spectroscopy. Dev Neurosci 2000, 22:463-471.

14. Warskulat U, Görg B, Bidmon HJ, Muller HW, Schliess F, Häussinger D: Ammonia-induced heme oxygenase- 1 expression in cultured rat astrocytes and rat brain in vivo. Glia 2002, 40:324-336.

15. Ganz R, Swain M, Traber P, DalCanto M, Butterworth RF, Blei AT: Ammoniainduced swelling of rat cerebral cortical slices: implications for the pathogenesis of brain edema in acute hepatic failure. Metab Brain Dis 1989, 4:213-223.

16. Zielinska M, Hilgier W, Law RO, Gorynski P, Albrecht J: Effects of ammonia in vitro on endogenous taurine efflux and cell volume in rat cerebrocortical minislices: influence of inhibitors of volume-sensitive amino acid transport. Neuroscience 1999, 91:631-638.

17. Voorhies TM, Ehrlich ME, Duffy TE, Petito CK, Plum F: Acute hyperammonemia in the young primate: physiologic and neuropathologic correlates. Pediatr Res 1983, 17:970-975

18. Willard-Mack CL, Koehler RC, Hirata T, Cork LC, Takahashi H, Traystman RJ, Brusilow SW: Inhibition of glutamine synthetase reduces ammoniainduced astrocyte swelling in rat. Neuroscience 1996, 71:589-599.

19. Norenberg MD, Jayakumar AR, Rama Rao KV, Panickar KS: New concepts in the mechanism of ammonia-induced astrocyte swelling. Metab Brain Dis 2007, 22:219-234.

20. Wilkinson SP, Arroyo V, Moodie H, Williams R: Proceedings: Endotoxaemia in fulminant hepatic failure. Clin Sci Mol Med 1974, 46:30P-31P.

21. Wyke RJ, Canalese JC, Gimson AE, Williams R: Bacteraemia in patients with fulminant hepatic failure. Liver 1982, 2:45-52.

22. Odeh M, Sabo E, Srugo I, Oliven A: Serum levels of tumor necrosis factoralpha correlate with severity of hepatic encephalopathy due to chronic liver failure. Liver Int 2004, 24:110-116.

23. Wright G, Davies NA, Shawcross DL, Hodges SJ, Zwingmann C, Brooks HF, Mani AR, Harry D, Stadlbauer V, Zou Z, Williams R, Davies C, Moore KP, Jalan R: Endotoxemia produces coma and brain swelling in bile duct ligated rats. Hepatology 2007, 45:1517-1526.

24. Sinke AP, Jayakumar AR, Panickar KS, Moriyama M, Reddy PV, Norenberg MD: NFkappaB in the mechanism of ammonia-induced astrocyte swelling in culture. J Neurochem 2008, 106:2302-2311.

25. Ducis I, Norenberg LO, Norenberg MD: The benzodiazepine receptor in cultured astrocytes from genetically epilepsy-prone rats. Brain Res 1990, 531:318-321.

26. Juurlink $\mathrm{BH}$, Hertz L: Plasticity of astrocytes in primary cultures: an experimental tool and a reason for methodological caution. Dev Neurosci 1985, 7:263-277.

27. Mans AM, Saunders SJ, Kirsch RE, Biebuyck JF: Correlation of plasma and brain amino acid and putative neurotransmitter alterations during acute hepatic coma in the rat. J Neurochem 1979, 32:285-292.

28. Swain M, Butterworth RF, Blei AT: Ammonia and related amino acids in the pathogenesis of brain edema in acute ischemic liver failure in rats. Hepatology 1992, 15:449-453.

29. Rama Rao KV, Reddy PVB, Tong X, Norenberg MD: Brain edema in acute liver failure: inhibition by L-histidine. Am J Pathol 2010, 176:1400-1408.

30. Kletzien RF, Pariza MW, Becker JE, Potter VR: A method using 3-O-methylD-glucose and phloretin for the determination of intracellular water space of cells in monolayer culture. Anal Biochem 1975, 68:537-544.

31. Baldwin AS Jr: The NF-kappa B and I kappa B proteins: new discoveries and insights. Annu Rev Immunol 1996, 14:649-683.

32. O'Grady JG, Williams R: Management of acute liver failure. Schweiz Med Wochenschr 1986, 116:541-544.
33. Jalan $R$, Williams $R$ : The inflammatory basis of intracranial hypertension in acute liver failure. J Hepatol 2001, 34:940-942.

34. Jalan R, Olde Damink SW, Hayes PC, Deutz NE, Lee A: Pathogenesis of intracranial hypertension in acute liver failure: inflammation, ammonia and cerebral blood flow. J Hepatol 2004, 41:613-620.

35. Shawcross D, Jalan R: The pathophysiologic basis of hepatic encephalopathy: central role for ammonia and inflammation. Cell Mol Life Sci 2005, 62:2295-2304.

36. O'Beirne JP, Chouhan M, Hughes RD: The role of infection and inflammation in the pathogenesis of hepatic encephalopathy and cerebral edema in acute liver failure. Nat Clin Pract Gastroenterol Hepatol 2006, 3:118-119.

37. Williams R, Smith MG: Liver transplantation: a clinical and immunological appraisal. Prog Liver Dis 1972, 4:433-446.

38. Lieberman AP, Pitha PM, Shin HS, Shin ML: Production of tumor necrosis factor and other cytokines by astrocytes stimulated with lipopolysaccharide or a neurotropic virus. Proc Natl Acad Sci USA 1989, 86:6348-6352.

39. Chang RC, Stadlin A, Tsang D: Effects of tumor necrosis factor alpha on taurine uptake in cultured rat astrocytes. Neurochem Int 2001, 38:249-254.

40. Bemeur C, Qu H, Desjardins P, Butterworth RF: IL-1 or TNF receptor gene deletion delays onset of encephalopathy and attenuates brain edema in experimental acute liver failure. Neurochem Int 2010, 56:213-215.

41. Barnum SR, Jones $J$, Benveniste EN: Interleukin-1 and tumor necrosis factor-mediated regulation of C3 gene expression in human astroglioma cells. Glia 1993, 7:225-236.

42. Croitoru-Lamoury J, Guillemin GJ, Boussin FD, Mognetti B, Gigout LI, Cheret A, Vaslin B, Le Grand R, Brew BJ, Dormont D: Expression of chemokines and their receptors in human and simian astrocytes: evidence for a central role of TNF alpha and IFN gamma in CXCR4 and CCR5 modulation. Glia 2003, 41:354-370.

43. Shafer RA, Murphy S: Activated astrocytes induce nitric oxide synthase-2 in cerebral endothelium via tumor necrosis factor alpha. Glia 1997, 21:370-379.

44. Kemler I, Fontana A: Role of IkappaBalpha and IkappaBbeta in the biphasic nuclear translocation of NF-kappaB in TNFalpha-stimulated astrocytes and in neuroblastoma cells. Glia 1999, 26:212-220.

45. Marcus JS, Karackattu SL, Fleegal MA, Sumners C: Cytokine-stimulated inducible nitric oxide synthase expression in astroglia: role of Erk mitogen-activated protein kinase and NF-kappaB. Glia 2003, 41:152-160.

46. Brahma B, Forman RE, Stewart EE, Nicholson C, Rice ME: Ascorbate inhibits edema in brain slices. J Neurochem 2000, 74:1263-1270.

47. Chan PH, Fishman RA, Lee JL, Quan SC: Arachidonic acid-induced swelling in incubated rat brain cortical slices. Effect of bovine serum albumin. Neurochem Res 1980, 5:629-640.

48. Jayakumar AR, Panickar KS, Murthy Ch R, Norenberg MD: Oxidative stress and mitogen-activated protein kinase phosphorylation mediate ammonia-induced cell swelling and glutamate uptake inhibition in cultured astrocytes. J Neurosci 2006, 26:4774-4784.

49. Staub F, Winkler A, Peters J, Kempski O, Kachel V, Baethmann A: Swelling, acidosis, and irreversible damage of glial cells from exposure to arachidonic acid in vitro. J Cereb Blood Flow Metab 1994, 14:1030-1039.

50. Reinehr R, Görg B, Becker S, Qvartskhava N, Bidmon HJ, Selbach O, Haas HL, Schliess F, Häussinger D: Hypoosmotic swelling and ammonia increase oxidative stress by NADPH oxidase in cultured astrocytes and vital brain slices. Glia 2007, 55:758-771.

51. Jayakumar AR, Rama Rao KV, Tong XY, Norenberg MD: Calcium in the mechanism of ammonia-induced astrocyte swelling. J Neurochem 2009, 109(Suppl 1):252-257.

52. Norenberg MD, Rama Rao KV, Jayakumar AR: Signaling factors in the mechanism of ammonia neurotoxicity. Metab Brain Dis 2009, 24:103-117.

doi:10.1186/1742-2094-7-66

Cite this article as: Rama Rao et al:: Marked potentiation of cell swelling by cytokines in ammonia-sensitized cultured astrocytes. Journal of Neuroinflammation 2010 7:66. 